\title{
SISTEM INFORMASI MANAJEMEN PEMINJAMAN (STUDI KASUS : PENGELOLAAN ASET DAN TATA RUANG TAMAN BUDAYA JAWA TENGAH)
}

\author{
Anggita Puspaningrum ${ }^{1}$, Endah Sudarmilah ${ }^{2}$. \\ ${ }^{1}$ Fakultas Komunikasi dan Informatika, Program Studi Informatika, Universitas Muhammadiyah Surakarta \\ email : anggitapuspaningrum@gmail.com \\ ${ }^{2}$ Universitas Muhammadiyah Surakarta \\ email : endah.sudarmilah@ums.ac.id
}

\begin{abstract}
Abstrak
Taman Budaya Jawa Tengah merupakan salah satu tempat pementasan ternama di Kota Surakarta. Pengelolaan aset dan tata ruang pada Taman Budaya Jawa Tengah saat ini masih dikategorikan dalam pengelolaan secara manual karena masih menggunakan papan tulis sebagai media pencatatan data peminjaman aset dan tata ruang yang menyebabkan kinerja belum optimal. Agar pengelolaan aset dan tata ruang bisa lebih optimal maka dibuatlah suatu sistem untuk proses pencatatannya. Sistem informasi diharapkan mendapatkan hasil prototype sistem yang menggambarkan fungsional perencanaan, pengadaan, penerimaan dan penempatan aset pada Taman Budaya Jawa Tengah. Metode yang digunakan adalah metode SDLC dengan pendekatan waterfall dengan memanfaatkan UML (unified modelling language) yang terdiri dari use case diagram, class diagram dan activity diagram. Penelitian ini mendapatkan menghasilkan sistem informasi manajemen penjadwalan aset dan tata ruang yang dapat diimplementasikan pada Taman Budaya Jawa Tengah.
\end{abstract}

\section{Kata Kunci : Aset, Informasi, Peminjaman, Ruang, Taman Budaya Jawa Tengah}

\section{Pendahuluan}

Dampak teknologi informasi telah membawa perubahan dan perkembangan dari berbagai bidang. Sehingga sistem informasi layanan juga harus ditingkatkan. Peminjaman dan pengelolaan aset dan tata ruang dari sebuah gedung pementasan adalah kegiatan yang bergerak dalam sektor ekonomi dan kebudayaan. Proses manajemen dan pencatatan data tidak bisa dipisahkan dengan suatu perkembangan teknologi informasi, dikarenakan setiap keputusan manajemen selalu membutuhkan dukungan dari teknologi informasi begitu pula dengan manajemen aset dan tata ruang. Tantangan ditekankan pada sistem informasi peminjaman yang masih menggunakan sistem manual yang masih membuang-buang waktu dalam mencari data karena menggunakan kertas sebagai media penyimpanan, sementara di sisi lain, layanan yang baik diperlukan termasuk layanan yang cepat, akurat dan tepat(Saputra, Inovera, \& Susanti, 2018; Yunita \& Devitra, 2017).

Proses sistematis yang digunakan untuk mempertahankan, meng-upgrade, dan mengoperasikan aset dengan carayang hemat bisa dilakukan dengan penciptaan, akuisisi, operasi, pemeliharan, rehabilitasi, dan penghapusan aset yang terdapat didalamnya dengan mengidentifikikasikan kebutuhan aset disebut dengan manajemen aset. Aset dan tata ruang dimiliki setiap perusahaan, organisasi maupun instansi pemerintahan, baik yang berwujud (tangible) maupun tidak berwujud (intagible). Aset dan tata ruang yang dimiliki harus bisa dikelola dengan baik sehingga memberikan manfaat tinggi bagi organisasi tersebut (Yunita \& Devitra, 2017).

Permasalahan yang ada salah satunya yaitu tentang penjadwalan ruang dan tata aset yang dirasa masih sangat sederhana, sehingga sering terjadi kesalahan pada pembagian dan informasi mengenai ketersediaan lokasi. Manajemen aset dengan menggunakan papan tulis dan pembukuan secara manual mengakibatkan data yang tercatat kurang efektif untuk dikelola, karena antara satu data dengan data yang lainnya bisa terduplikasi, dan harus melalui proses peruntutan ulang agar dapat diketahui dimana letak kesalahan yang terjadi. Oleh karena itu, terdapat ide dari penulis untuk 
mengimplementasikannya dalam sebuah Sistem Informasi Manajemen Aset dan Tata Ruang, sehingga untuk mencatat ketersediaan tempat atau aset ruang dari Taman Budaya Jawa Tengah dapat diketahui secara real time. Apabila ada pihak yang membutuhkan informasi tidak kesulit untuk mencari keberadaan aset tersebut. Perlu dirancang suatu sistem komputerisasi untuk mengatasi masalah tersebut. Sistem yang terkomputerisasi diharapkan dapat membantu pengelolaan agar lebih efektif dan efisien daripada pengelolaan secara manual. Sistem yang terkomputerisasi dapat membantu pengelolaan data, kerugian dalam transaksi, dan banyak manfaat positif lainnya. Sistem informasi pengelolaan aset dan tata ruang adalah sistem yang dapat memproses data pemesanan, sehingga memudahkan pelanggan untuk melihat ketersediaan aset dan tata ruang secara real-time. Aplikasi ini juga memudahkan pemerintah dan pengelola untuk mendapatkan laporan dengan cepat dan mudah (Saputra et al., 2018).

Berdasarkan paparan tersebut di atas, maka penulis tertarik untuk mengangkat sebuah penelitian yang berjudul "Sistem Informasi Manajemen Penjadwalan Ruang Pementasan (Studi Kasus : Pengelolaan Aset dan Tata Ruang Taman Budaya Jawa Tengah)" (Agung Aryanto, 2017; Imtihan, 2015; Mara Destiningrum, 2017; Puspita, Arini, \& Masrurah, 2017; Suhartono, 2015; Wiga Ayu Puspaningrum, Arif Djunaidy, 2013).

Diketahui bahwa sistem informasi memainkan peran penting dalam bidang apapun, baik perusahaan skala kecil, skala menengah, bahkan skala besar sekalipun ataupun lembagalembaga yang bergerak di bidang manapun di dalam menyampaikan suatu informasi (Agung Aryanto, 2017; Heru Supriyono, Achmad Munawir Noviandri, 2017; Januhari, 2015; Limantara, Cahyo, Purnomo, \& Mudjanarko, 2017; Mara Destiningrum, 2017; Mizwar, 2012; Suhartono, 2015; Wahyuni, 2017; Wiga Ayu Puspaningrum, Arif Djunaidy, 2013; Yunita \& Devitra, 2017).

Sistem informasi sebagai media pendukung untuk menyampaikan informasi kepada masyarakat, oleh karena itu sistem informasi harus efektif, efisien dan mudah (user friendly) dalam penggunaanya.
Taman Budaya Jawa Tengah (TBJT) atau juga disebut Taman Budaya Surakarta (TBS) adalah Taman Budaya Jawa Tengah merupakan salah satu tempat pementasan ternama di Kota Surakarta. Didirikan oleh Pemerintah Provinsi Jawa Tengah.

Penulis menyampaikan masalah mendasar mengenai bagaimana membangun Penjadwalan Sistem Informasi, sehingga dapat mendukung penjadwalan seperti yang diharapkan. Penulis melakukan analisis terhadap kelemahan sistem lama yang sedangan berjalan sehingga bisa dilengkapi dengan sistem baru yang lebih baik lagi.

Sistem Informasi ini dirancang agar dapat digunakan oleh pihak Taman Budaya Jawa Tengah sendiri dalam mempermudah pendataan manajemen aset sarana dan prasarana Taman Budaya Jawa Tengah, serta bermanfaat untuk khalayak guna memberikan informasi mengenai pementasan maupun ketersediaan ruang dan aset bagi para siswa, mahasiswa ataupun pekerja seni yang ingin mengadakan pementasan, tanpa perlu hadir langsung untuk melihat jadwal atau ruangan yang tersedia di Taman Budaya Jawa Tengah.

\section{Metode}

Metode yang digunakan adalah metode SDLC dengan pendekatan waterfall dengan memanfaatkan UML (unified modelling language) yang terdiri dari use case diagram dan activity diagram. SDCL terdiri dari beberapa fase yang dimulai dari fas perencanaan, analisis, perancangan, implementasi hingga pemeliharaan sistem (Fitriana, Moengin, \& Riana, 2016). Penelitian ini mendapatkan menghasilkan sistem informasi manajemen penjadwalan aset dan tata ruang yang dapat diimplementasikan pada Taman Budaya Jawa Tengah. Metode pengembangan sistem ini penulis menerapkan model Waterfall (Arifin, Deddy, \& Satria, 2013; Heru Supriyono, Achmad Munawir Noviandri, 2017; Mara Destiningrum, 2017; Puspita et al., 2017; Yunita \& Devitra, 2017). Sistem informasi manajemen aset dan tata ruang Taman Budaya Jawa Tengah diharapkan sesuai dengan rencana yang telah di sepakati. Proses perancangan dan pembuatan sistem informasi manajemen aset dan tata ruang Taman Budaya Jawa Tengah disimulasikan 
dalam sebuah diagram alir seperti terlihat pada Gambar 1 .

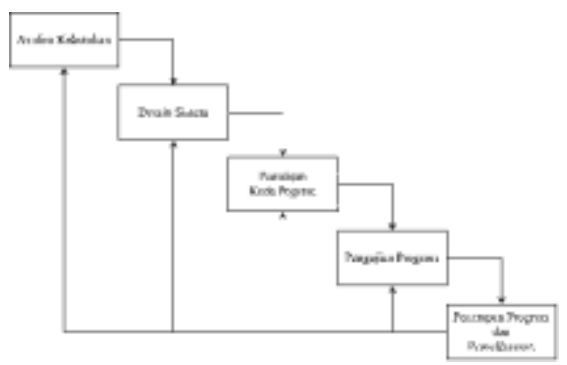

Gambar 1. Diagram Alir

\subsection{Analisis dan Pengumpulan Data}

Proses pengumpulan data dengan cara wawancara dengan pengelola Taman Budaya Jawa Tengah guna untuk memperoleh data yang di butuhkan, data tersebut antara lain : profil, letak aset dan tata ruang, denah lokasi dan harga.

\section{a. Kebutuhan Fungsional}

- Sistem dapat membantu dalam input pendataan aset, tata ruang, transaksi peminjaman, transaksi pembayaran

- Sistem menyediakan fasilitas yang memungkinkan user atau penggunanya mendapatkan informasi mengenai Taman Budaya Jawa Tengah

- Sistem dapat menghitung biaya kebutuhan

- Sistem dapat menampilkan ketersediaan ruang dan aset

- Sistem dapat menginfokan mengenai kualifikasi dan fasilitas setiap ruang

- Sistem dapat menampilkan laporan peminjaman dan pembayaran

\section{b. Kebutuhan Non Fungsional}

- Sistem dapat diakses dengan software web browser diantaranya Microsoft Edge, Internet Explorer, Google Chrome dan Mozilla Firefox

- Pengguna dapat mengakses, mengisi dan menampilkan form untuk pemesanan berlangsung maksimal 60 menit, lebih dari itu maka sistem akan terhenti

- Sistem dapat memastikan data yang digunakan oleh pengguna terlindungi dari akses yang tidak berwenang

- Sistem memiliki interface yang mudah dipahami

\subsection{Desain Sistem (Perancangan Sistem) \\ A. Use Case Diagram}

- User

○ Melakukan registrasi pengguna

- Dapat melihat menu dan interface utama dari sistem

- Melihat informasi mengenai ketersediaan ruang dan aset dari Taman Budaya Jawa Tengah

- Dapat melakukan pemesanan ruang dan aset pada website tersebut

- Admin

- Melakukan login untuk masuk sebagai admin pada sistem

- Mengelola informasi mengenai ruangan pada Taman Budaya Jawa Tengah

- Mengelola pemesanan dan pembayaran dari user yang akan melakukan peminjaman pada ruang atau aset Taman Budaya Jawa Tengah

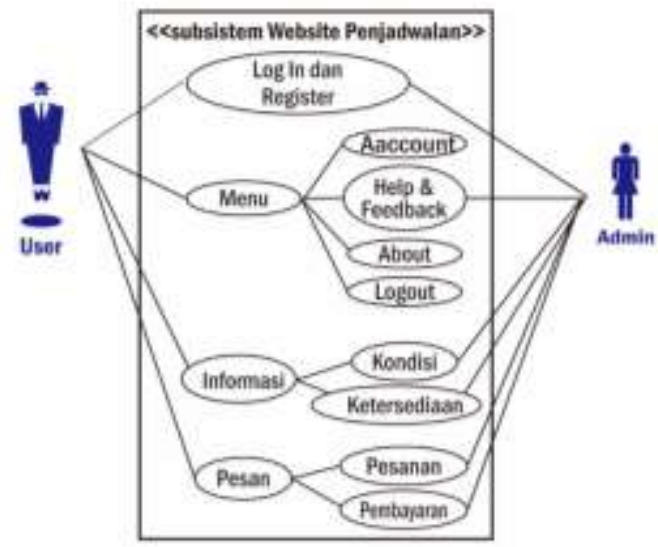

Gambar 2. Use case diagram 
Gambar 2. menjelaskan bahwa user selaku pengguna dapat menambahkan data peminjaman serta kebutuhan acara melalui sistem informasi yang telah di buat secara online. Selanjutnya, sistem memberikan respon yang diberikan kepada admin sesuai data yang telah di inputkan oleh pengguna, ketika data sudah di verifikasi masyarakat atau user dapat melihat informasi mengenai kegiatan atau ketersediaan aset dan tata ruang dari Taman Budaya Jawa Tengah.

\section{B. Entity Relationship Diagram}
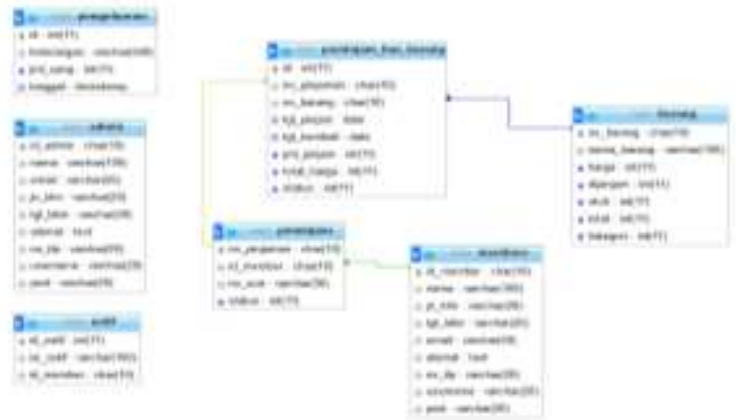

Gambar 3. Entity Relationship Diagram

Gambar 3. Merupakan entitas hubungan antar data satu dengan yang lainnya, diagram ini berdasarkan dengan keadaan yang sesungguhnya sesuai dengan database yang akan dibuat nantinya untuk sistem.

\section{Activity Diagram}



Gambar 4. Activity Diagram Sign Up

Gambar 4. Menjelaskan tentang cara kerja sistem di sisi user untuk registrasi atau mendaftarkan akun ke website Taman Budaya Jawa Tengah yang akan digunakan dalam melakukan peminjaman

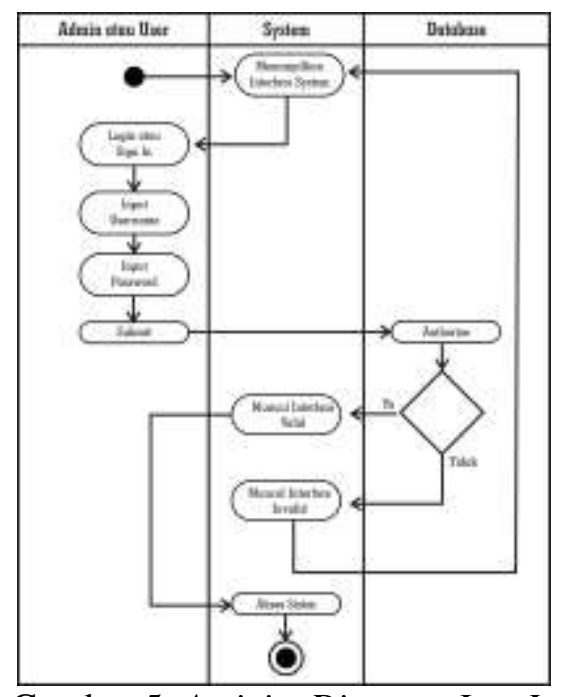

Gambar 5. Activity Diagram Log In

Gambar 5. Menjelaskan tentang cara kerja sistem di sisi user dan admin untuk masuk ke website Taman Budaya Jawa Tengah

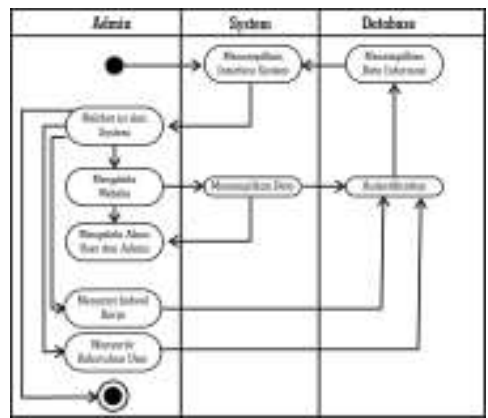

Gambar 6. Activity Diagram admin sistem internal

Gambar 6. Menjelaskan tentang cara kerja sistem di admin untuk mengelola data internal dari website Taman Budaya Jawa Tengah

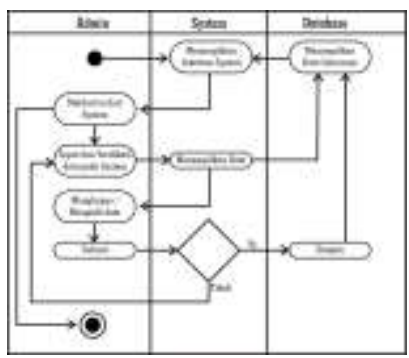

Gambar 7. Activity Diagram admin sistem eksternal peminjaman 
Gambar 7. Menjelaskan tentang cara kerja sistem di sisi admin untuk mengelola peminjaman ruang dan aset pada website Taman Budaya Jawa Tengah

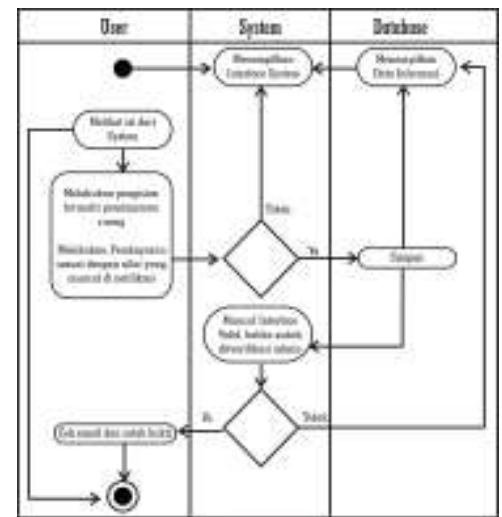

Gambar 8. Activity Diagram user untuk meminjam ruang

Gambar 8. Menjelaskan tentang cara kerja sistem di sisi user yang akan digunakan dalam melakukan peminjaman aset dan ruang pada website Taman Budaya Jawa Tengah secara online

\subsection{Penulisan Kode Program}

Tahap penerjemahan rancangan ke dalam kode program untuk diimplementasikan dalam proses pembuatan sistem informasi agar perintah-perintah tersebut bisa dimengerti oleh komputer.

\subsection{Pengujian Program}

Tahap ini digunakan setelah sistem sudah dibuat, tujuannya untuk menguji softwae agar terbebas dari eror. Pengujian ini dilakukan dengan cara Black box, dengan menguji atau cek masukan dan keluaran sistem apakah sudah sesuai atau belum. Pengujian bertujuan sebagai penilaian apakah sistem yang dikembangkan dapat dinyatakan berhasil atau gagal dan untuk memperlihatkan keakuratan fitur utama di dalam sistem (Fitri \& Fatmawati, 2019).

\subsection{Penerapan Program dan Pemeliharaan}

Ketika sistem sudah berhasil dibuat, maka tahapan selanjutnya adalah penerapan dan pemeliharaan dari sistem informasi tersebut. Dapat dilakukan dengan perbaikan, pengelolaan, perubahan, ataupun pengembangan dari sistem informasi itu sendiri.

\section{Hasil dan Pembahasan}

Tahap ini sistem informasi telah selesai dikembangkan dengan tampilan menu dan beberapa fitur yang akan memudahkan user dalam menggunakannya.

\subsection{Halaman Utama}

Halaman utama ditunjukkan dalam Gambar 9 yang merupakan tampilan awal ketika sistem diakses pada web browser. Halaman ini terdapat menu yang berisi login yang nantinya digunakan user untuk masuk kedalam menu selanjutnya dengan menggunakan email dan password.

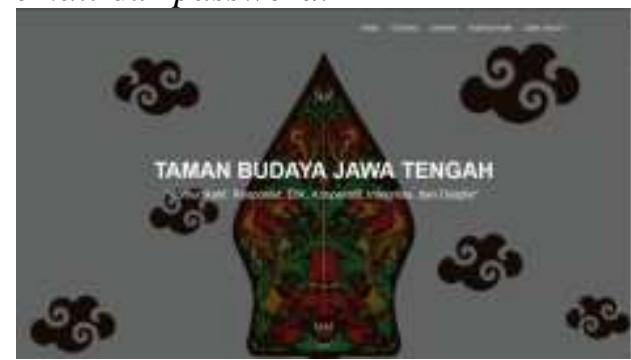

Gambar 9. Halaman Utama

\subsection{Halaman Login}

Halaman login yang ditunjukan dengan Gambar 10 berfungsi untuk jembatan masuk ke sistem atau halaman dashboard, dapat digunakan untuk login admin atau user.

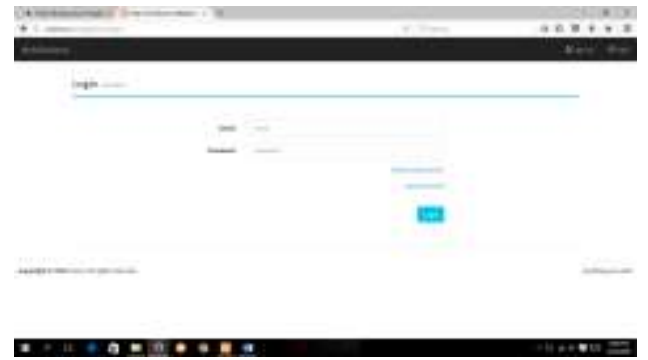

Gambar 10. Halaman Login

\subsection{Halaman Admin}

Halaman ini hanya admin saja memiliki hak akses secara penuh. Halaman ini membutuhkan login dari admin sistem sehingga hanya admin yang bisa mengaskses. Fitur pada halaman ini terdiri dari beberapa submenu. Submenu tersebut adalah menu utama, persediaan, peminjaman, pemberitahuan, pengeluaran, laporan dan grafik, serta 
daftar member ditunjukkan pada Gambar 11.

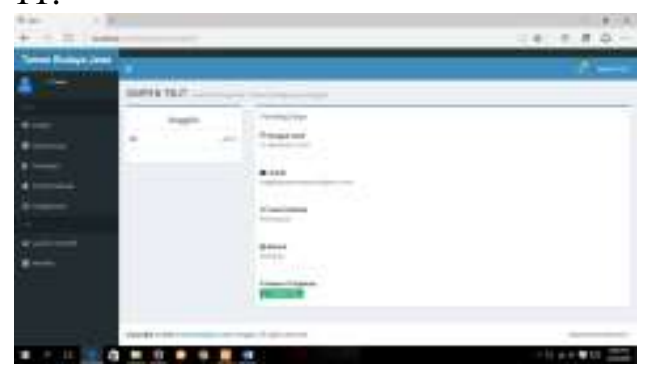

Gambar 11. Halaman Admin

\subsection{Halaman Peminjam atau User}

Gambar 12 menampilkan halaman peminjam membutuhkan login dari akun peminjam untuk mendapatkan hak akses. Fasilitas atau tools yang terdapat pada halaman ini ada tiga diantaranya menu profil diri yang berisi data diri dari peminjam. Menu selanjutnya adalah form peminjaman, pada menu ini peminjam bisa mendapatkan data aset dan tata ruang beserta jumlah dan informasi mengenai kertesediaan dan kondisi sekaligus dapat melakukan peminjaman secara langsung. Menu yang terakhir adalah status peminjaman, pada menu ini peminjam dapat mencetak bukti peminjaman ketika peminjaman sudah diterima oleh admin.

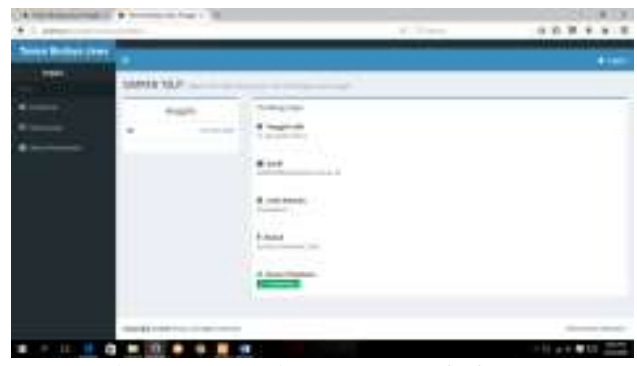

Gambar 12. Halaman Peminjam atau user

\subsection{Daftar Ketersedian Aset dan Ruang}

Daftar ketersediaan aset dan ruang ini mengizinkan peminjam untuk melakukan peminjaman lebih dari satu aset yang ditunjukkan pada Gambar 13 . Peminjam juga dapat memasukkan tanggal awal peminjaman dan tanggal pengembalian yang digunakan sistem untuk membatasi lama waktu peminjaman serta jumlah asetnya. Setelah itu peminjam dapat memilih pembayaran lewat rekening dengan melakukan upload bukti pembayaran atau pembayaran secara langsung.

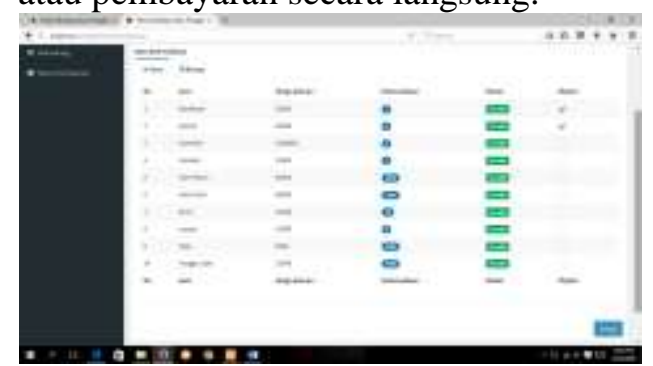

Gambar 13. Tabel Ketersediaan Aset dan Ruang

\subsection{Halaman Peminjaman}

Halaman ini berisi daftar data peminjaman dari semua peminjam yang hanya bisa diakses oleh admin ditunjukkan pada Gambar 14. Fitur yang terdapat pada halaman ini adalah melakukan konfirmasi peminjaman, admin bisa menerima pinjaman atau menolaknya. Kemudian peminjam akan mendapatkan notifikasi pada halaman peminjaman.

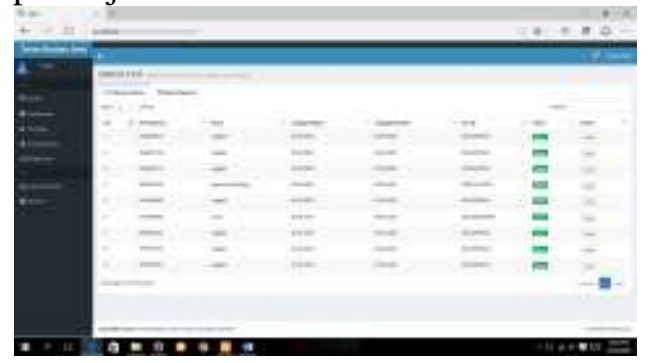

Gambar 14. Halaman Peminjaman

\subsection{Halaman Pengembalian}

Halaman yang berfungsi menampilkan data pengembalian berisi rincian pengembalian berikut biaya total yang harus dibayarkan. Fitur nota di bagian kanan berisi rincian total biaya yang harus dibayar dan dapat dicetak sebagai bukti pengembalian serta pembayaran yang valid ditampilkan pada Gambar 15 .

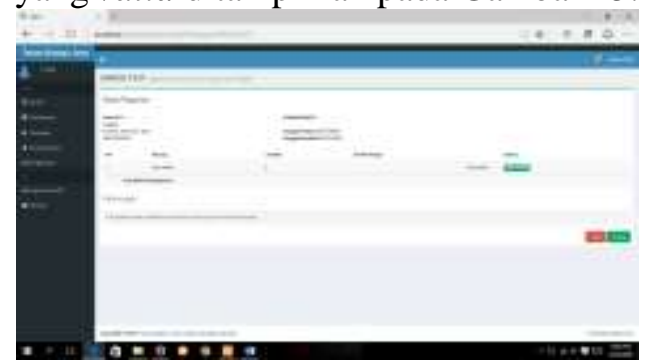

Gambar 15. Halaman Pengembalian 


\subsection{Laporan dan Grafik}

Gambar 16 menampilkan laporan keuangan peminjaman yang merupakan fitur yang terdapat dalam sistem informasi ini. Laporan ini dapat diatur sesuai bulan atau tahun yang diingikan. Fitur unduh dalam halaman ini memungkinkan admin untuk unduh atau penyimpanan laporan secara offline dalam bentuk file. Terakhir adalah fitur cetak dalam halaman ini memungkinkan admin untuk mencetak laporan secara langsung.

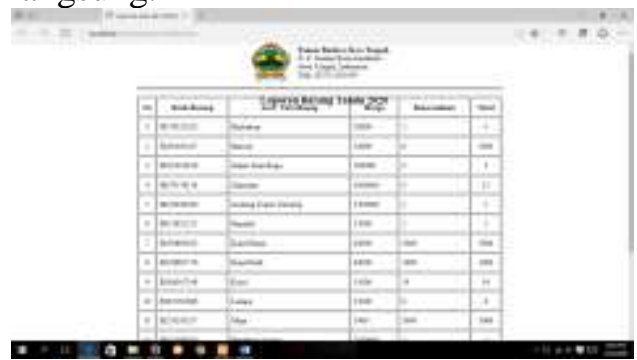

Gambar 16. Cetak Laporan

3.9 Pengujian Blackbox

Untuk memastikan sistem yang dikembangkan berjalan dengan baik atau tidak dilakukan pengujian black box. Hasil pengujian black box menyatakan bahwa sistem dapat berjalan sesuai dengan fungsi dan fiturnya sesuai dengan rancangan awal sistem.

\subsection{Pengujian SPSS}

Uji normalitas digunakan untuk mengetahui data yang akan dianalisis berdistribusi normal atau tidak. Secara fundamental, data yang berdistribusi normal dapat diketahui melalui bentuk histogram seperti lonceng. Terdapat banyak uji normalitas untuk mengetahui distribusi data.

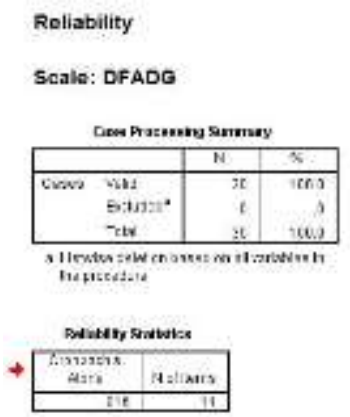

Gambar 17. Hasil Pengujian SPSS
Berdasarkan gambar 17 pengelolaan kuisioner menggunakan SPSS yang disebar kepada 30 responden menghasilkan nilai rata-rata 81,6. Dalam hal ini maka sistem termasuk kedalam kategori Valid.

\subsection{Pengujian SUS}

Menurut Brooke (1986), pengujian SUS terdiri dari sepuluh pernyataan sederhana dengan lima poin skala Likert yaitu poin 1 berati Sangat Tidak Setuju (STS) hingga poin 5 berati Sangat Setuju (SS). Penghitungan hasil SUS sebagai berikut :

1) Perhitungan nilai skor memperhatikan angka ganjil atau genap dari setiap pernyataan.

2) Pernyataan nomor ganjil dihitung dari nilai jawaban dikurangi 1 atau $(\mathrm{X}-1)$, pernyataan nomor genap adalah 5 (5-X) dikurangi dengan pernyataan yang dipilih.

3) Nilai diperoleh dikalikan 2.5 setiap skor lalu totalnya dijumlahkan.

4) Klasifikasi rata-rata nilai skor :

a) Usable, nilai diatas 81,6

b) Marginal,rata-rata nilai SUS antara 50-81,6 memiliki arti diperlukan peningkatan sistem yang telah dikembangkan.

c) Unacceptable, jika rata-rata nilai SUS dibawah 50 yang berarti sistem yang dikembangkan tidak dapat diterima.

Pengelolaan kuisioner menggunakan SUS yang disebar kepada 30 responden menghasilkan nilai ratarata 81.37097. Dalam hal ini maka sistem termasuk kedalam kategori Usable.

\section{Kesimpulan dan Saran Kesimpulan}

Berdasarkan pada pengujian Black Box yang telah dilakukan, sistem dapat berjalan sesuai dengan fungsi dan fitur yang telah dirancang sejak awal penelitian. Sistem dapat melakukan pencatatan data penduduk dan melayani 
pembuatan surat menyurat. Sedangkan berdasarkan kuisioner SPSS diperoleh nilai rata-rata 81,6 dan dapat disimpulkan bahwa sistem termasuk dalam kategori Valid. Selain itu, berdasarkan kuisioner pengujian SUS diperoleh nilai rata-rata 81.37097 dan dapat disimpulkan bahwa sistem termasuk dalam kategori Excellent atau Usable.

\section{Saran}

Diharapkan dalam pengembangan selanjutnya sistem ini dapat bermanfaat dan bisa menampilkan informasi yang lebih akurat dan informatif kedepannya.

\section{Daftar Pustaka}

Agung Aryanto. (2017). Analisi dan Perancangan Sistem Informasi Penjadwalan Pasien Keluarga Berencana Pada Klinik Bersalin Sarbini Dewi Yogyakarta. Naskah Publikasi, (6), 67-72.

Arifin, G. G., Deddy, A., \& Satria, E. (2013). Pengembangan Sistem Informasi Pemesanan Kamar Hotel Berbasis Web Menggunakan Metodologi Rapid Application Development. Jurnal STT-Garut, ISSN: 2302-7339, 10(1), 1-9.

Fitri, K. U., \& Fatmawati, A. (2019). Sistem Informasi Pelanggan pada Bengkel Marno Jaya Motor. Emitor: Jurnal Teknik Elektro, 19(1), 29-35.

https://doi.org/10.23917/emitor.v1 9i1.7529

Fitriana, R., Moengin, P., \& Riana, M. (2016). Information system design of inventory control spare parts maintenance (valuation class 5000) (case study: Plant kw). IOP Conference Series: Materials Science and Engineering, 114(1), 0-10. https://doi.org/10.1088/1757899X/114/1/012076

Heru Supriyono, Achmad Munawir Noviandri, Y. E. P. (2017). Penerapan Sistem Informasi Berbasis Komputer Untuk Pengelolaan Aset Bagi SMP Muhammadiyah 1 Kartasura. The 6th University Research Colloquium 2017, 59-70.

Imtihan, K. (2015). Perencanaan Strategi Sistem Informasi Pendidikan Pada Sekolah Tinggi Manajemen Informatika dan Komputer ( STMIK ) Lombok. Bianglala Informatika, 3(2), 7378.

Januhari, N. N. U. (2015). Perancangan Sistem Informasi Peminjaman Penggunaan Ruangan pada STMIK STIKOM Bali. Jurnal Sistem Dan Informatika (JSI), 9(2), 86-94. Retrieved from http://jsi.stikom-

bali.ac.id/index.php/jsi/article/view /31

Limantara, D. A., Cahyo, Y., Purnomo, S., \& Mudjanarko, S. W. (2017). Pemodelan Sistem Pelacakan LOT Parkir Kosong Berbasis Sensor Ultrasonic Dan Internet Of Things ( IOT ) Pada Lahan Parkir Diluar Jalan. Seminar Nasional Sains Dan Teknologi, 1(2), 1-10.

Mara Destiningrum, Q. J. A. (2017).

Sistem Informasi Penjadwalan Dokter Berbassis Web Dengan Menggunakan Framework Codeigniter (Studi Kasus: Rumah Sakit Yukum Medical Centre). Teknoinfo, 11(2), 6-13. Retrieved from http://ejurnal.teknokrat.ac.id/index. php/teknoinfo/article/view/24

Mizwar, A. (2012). Banjarbaru, Kota Sistem, Menggunakan Geografis, 
Informasi. Issn 1978-8096, 8, 1622.

Puspita, R. M., Arini, A., \& Masrurah, S. U. (2017). Pengembangan Aplikasi Penjadwalan Kegiatan Pelatihan Teknologi Informasi Dan Komunikasi Dengan Algoritma Genetika (Studi Kasus: Bprtik). Jurnal Online Informatika, 1(2), 76-81. https://doi.org/10.15575/join.v1i2. 43

Saputra, F. K., Inovera, R. A., \& Susanti, E. (2018). Web-based futsal field reservation system. Journal of Information Systems \& Applied Computer Science, 26140918, 7-10.

Suhartono, E. (2015). DENGAN ALGORITMA GENETIKA ( Studi Kasus di AMIK JTC Semarang ). Infokam, 2, 132-146.

Wahyuni, U. (2017). Rancang Bangun
Sistem Informasi Penjadwalan Kunjungan Narapidana Di Lembaga Pemasyarakatan Klas I Di Kabupaten Jeneponto Sulawesi Selatan SKRIPSI Diajukan Untuk Memenuhi Salah Satu Syarat Meraih Gelar Sarjana Komputer pada Jurusan Sistem Informasi Fakulta.

Wiga Ayu Puspaningrum, Arif Djunaidy, dan R. A. V. (2013). Penjadwalan Mata Kuliah Menggunakan Algoritma Genetika, Algoritma Informasi, Sistem Pendahuluan, I. JURNAL TEKNIK POMITS, 2(1), 127-131.

Yunita, I., \& Devitra, J. (2017). Informasi Manajemen Aset Pada Smk Negeri 4 Kota Jambi. Analisis Dan Perancangan Sistem Informasi Manajemen Aset Pada Smk Negeri 4 Kota Jambi, 2(1). 